University - Industry Relations $\mid 59$

\title{
University - Industry Relations: A Thrust for Transformation of Knowledge and Economic Acceleration
}

\author{
Dr. Shreeram Lamichhane \& Dr. Tanka Nath Sharma*
}

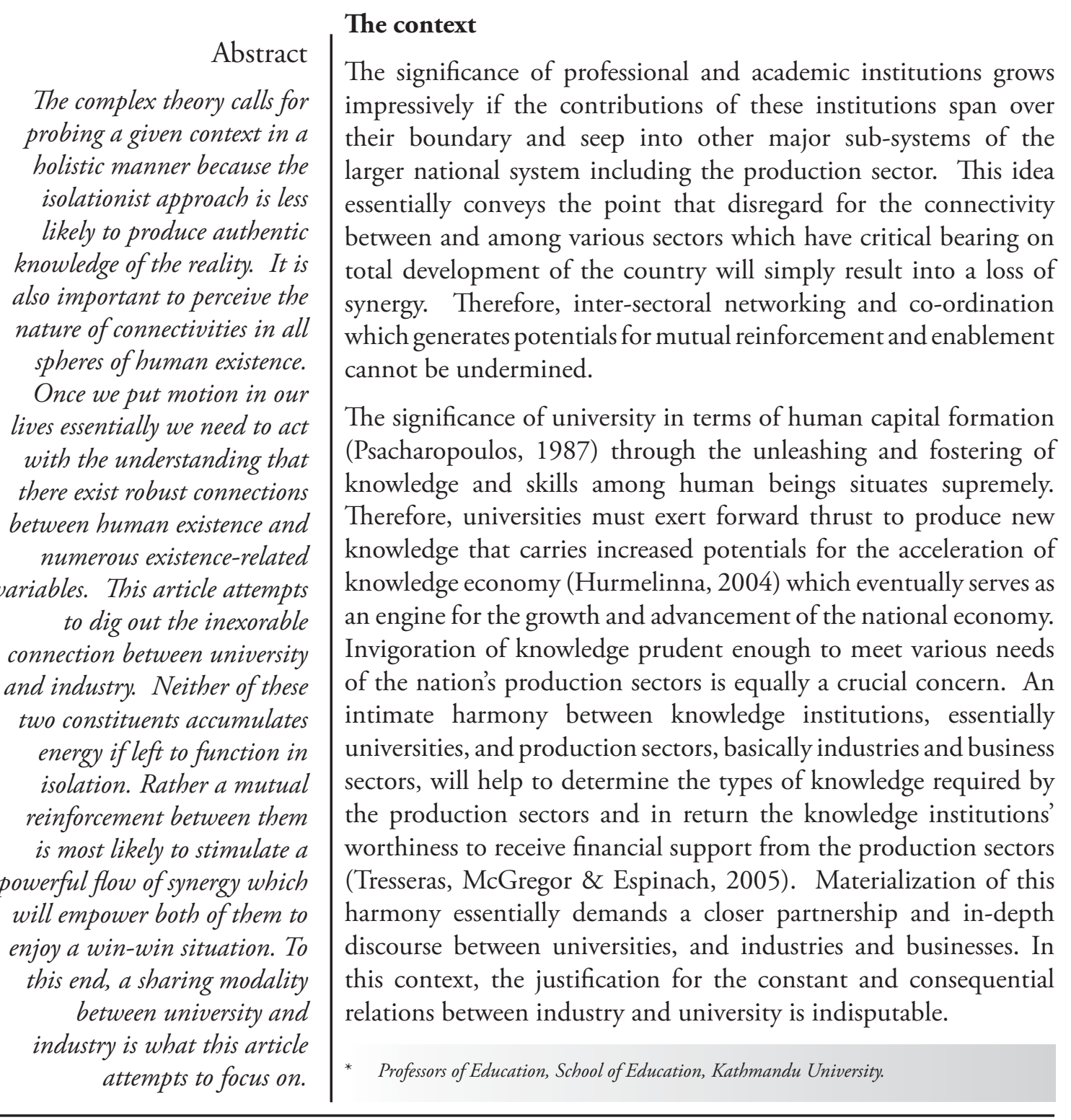

Journal of Education and Research Vol. 2, 2010 
60

Shreeram Lamichhane \& Tanka Nath Sharma

\section{Need}

In a rapidly changing industrial environment which is the consequence of new innovations and inventions the industrial enterprises have to face sharp competition and to cope with such competition fostering of industrial competences is crucial. As Otala (1994) states "Competence has become a crucial element of competitiveness" (p. 13). In addition, as a result of the impact of faster technological changes the current industrial environment has to face turbulent dynamics. In order to get along with this turbulence the employees in the production sectors need continuous updating and upgrading of their knowledge base and skills. Similarly, production sectors need to espouse flexibility. Otala (1994) suggests the importance of two types of flexibility - operational flexibility and strategic flexibility. He defines operational flexibility as "good working competence and capabilities that allow the organizations effectively to provide highquality products and services with the variety and speed that customers require" (p. 13).

Essentially, operational flexibility is possible in an organizational environment where a blend of three important elements - decentralization, flexible operating structure, and operation capabilities -- is prevalent. Strategic flexibility, on the other hand, as Otala (1994) views, is "the ability to seize new market opportunities and adapt rapidly to market changes". For this purpose the organization would require a professionally strong force having positive attitude and competency towards developing new functional capabilities and being fully aware of the requirements in the contemporary market.

In essence, in order to emerge successfully in the competitive production process it is imperative to heighten visionary and performance capabilities of the workforce, to adopt flexibility in the management system, and to keep abreast with the turbulent dynamics in the production sectors. In addition, the relevance of research and development so as to be critically aware of the emerging needs and challenges, as well as opportunities need to be accounted for.

The needs explained above calls for perpetual preparedness of all the authorities associated with the production process. Understandably, strengthening service and production sectors' capabilities, leaving aside the initiatives to be taken by the internal management system, will require the involvement of other knowledge producing institutions, for example, universities and similar other educational establishments. Obviously, the involvement of universities unless geared up meaningfully through the generation of new knowledge having greater relevance for industries will not carry any significance (Srinivas \&Villamgg, 2005). Therefore, to be able to contribute value-added knowledge inputs to industries there are some imperatives that universities should observe conscientiously.

Ping (2003) suggested three distinct imperatives for universities in order to be able to contribute knowledge inputs compatible with the needs of industries in the competitive market. These imperatives are; the imperative to modernize, the imperative to exchange, and the imperative of identity. Ping (2003) interprets the imperative to modernize in this way "The modern university continues the search for new knowledge and discovery as a basic task of the university while at the same time playing a key role in the transfer of technology from the campus to the production sector". The implication of this statement is that a university as a producer of knowledge should strive for innovating new knowledge that is significant not only for the academic purpose but is potential also to capacitate the production sector, more specifically the industrial sector. The imperative to exchange and the imperative of identity, as professor ping (Ping, 2003) highlights, need to be increasingly focused upon, primarily, to redraw the boarder of the university which links it with the society and the marketplace and, secondly, for this purpose an impressive identity of the university should 
be established for which the university should encompass within its academic realm of varied interests, thus, universities can redirect their focus on generating interest-specific and culturespecific knowledge.

Actually, in the discourse of development in modern era knowledge takes the center stage. In order to secure a broader edge in the competitive world generation of relevant and pertinent knowledge, processing it along the needs of the diverse service and production culture, and dissemination of the processed knowledge expansively are crucial components of knowledge management. Undoubtedly the university is the key role player in this context. On the other hand, the industrial sector also should strive for positioning itself as a forward runner in the competitive market context. For gaining strength to emerge successfully this sector should open up a wider horizon to developing networks and interconnections with the universities. In fact, a synergistic relationship between the knowledge culture and the production culture will essentially bring precious currencies to the national economy.

Obviously, the interactive relationships between universities and the industrial sector should have sustainable characteristic for which as Goktepe (2004) views, "The interaction and relations between university and industry need to be institutionalized and regulated in order to eliminate the cultural clashes as well as to endow both sides and society with benefits" (p. 6). Furthermore, he argues, in situations affected by weak interface settings between university and industry the state should take the lead role in order to ensure an easy flow of ideas and people between these two entities.

Justifications concerning the need for universityindustry relations can be made on the basis of shared benefits between university and industry. The benefits that universities gain, according to Gray (2000) and Ilyas (2004), are (1) new funding sources for research; (2) new learning and employment opportunities for graduates; (3) increased motivation for innovation; (4) new drive for advancing research endeavors. On the other hand, industries could make gains through (1) easier access to university graduates and faculty members; (2) research results and outcomes; (3) intellectual property rights (Tresseras, McGregor $\&$ Espinach, 2005). These potential gains which can be derived through the university-industry interactions essentially activate the innovative system generating more dynamism and efficiency in both university and industry fronts. This strength would not materialize if each one of these two fronts works separately. Meanwhile, it is not prudent to assume that the mutual sharing between university and industry is infallible. Misunderstandings leading to conflicts would degenerate the process of cooperation and impede the relations between university and industry. Conflicts tend to arise due to irrationalized sharing of benefits and gainful results as well as due to differences in organizational cultures, misjudgment of contributions made by the partners and underachievement in the fulfillment of expectations (Tresserras et.al, 2005).

\section{Dimensions of linkages and collaboration}

There are many types of linkages that industry can make with the university. Informal linkages may consist of faculty consulting, student job placement, and student internships. More formal linkages with the university include contract research, research parks, industrial $\mathrm{R}$ \& D consortia, and industry-university research centers (Rahm, 2000). Gray (2000) provided three major dimensions of university industry collaboration: primary purpose, organizational formality, and the relationship to the university.

According to Hernández-Cuevas (2006), a linkage mechanism can have one of five primary purposes: research, knowledge/technology transfer, product/process development, brokerage liaison, or multipurpose. A linkage mechanism with the purpose of research would create new knowledge by using a method of 
systematic inquiry. A linkage with the purpose of knowledge/technology transfer would focus on transfer of knowledge or technology that have already existed or on the making by undertaking activities such as education, training, research or consultation.

Koester and Gray (1990 as cited in HernándezCuevas, 2006) stated that product/process development linkages assist to the development and marketing of new products and processes. Liaison linkages facilitate the relationship between the industry and university. Periodic interactive discourse for borrowing perception, inputs for curricular improvement, facilitating student job placement, advice to improve performance in the industry and maintaining relationship and linkages between university and industries are the main purposes of liaison linkages. Finally, multipurpose linkages fulfill more than one of these purposes.

According to Hernández-Cuevas (2006), the second dimension in which linkages can vary is in the degree of formality. Formality can be described as the extent to which the linkage mechanism possesses the structures, procedures, and infrastructure one associates with welldefined organizations or organizational unit. Standard linkage mechanisms are the most formal and have established goals, administrative staff and leadership hierarchy. Adaptive linkage mechanisms are similar to standard linkages except they have a more limited administrative and physical infrastructure. Shadow linkage mechanisms generally have no administrative and physical infrastructures and may exist as an organization on paper only. Finally, informal linkage mechanisms have no organizational characteristics. Examples of this type of linkage are research contracts between a professor and a firm, internship programs, and faculty consulting to firms (Ilyas, 2004).

The final dimension of university-industry collaboration is to develop and activate the relationship of the linkage mechanism as a part of university structure aligned with the norms and goals of the university within a hierarchical system of control. Cooperative extension programs, which are at many universities in the west, are examples of this type of linkage. In some cases, semi-autonomous linkage mechanisms represented by both university and industry are created which have a higher level of independence from the university. Such semi-autonomous structures are usually in charge of determining their own budget, goals, and administrative operations. An example of this type of linkage is the Industry-University Research Center. Finally independent linkage mechanisms are almost completely separate from the university. There is usually an agreement made with the University for the use of building space or other resource. Industrial research parks or business incubation centers within the university premises are examples of an independent linkage mechanism (Hernández-Cuevas, 2006).

\section{Current status and gap}

The UNESCO's World Declaration and Framework for Priority Action for Change and Development in Higher Education on its 17th Article emphasizes the importance of partnerships and strategic alliances between the universities and the stakeholders in the world of work and stated:

"Partnership and alliances amongst stakeholders - national and institutional policy-makers, teaching and related staff, researchers and students, and administrative and technical personnel in institutions of higher education, the world of work, community groups - is a powerful force in managing change. Also, non-governmental organizations are key actors in this process. Henceforth, partnership, based on common interest, mutual respect and credibility, should be a prime matrix for renewal in higher education" (UNESCO, 1998).

Universities are expected to be ready to engage in continuous improvement through innovation and change for preparing people with new 
abilities, knowledge and credibility in a constantly changing environment and also contribute to build the future of our nation. This has been realized to be possible through reinforcing the collaboration between the higher education institutions and the working world.

\section{Future pointers}

Both university and industry are benefitted and create synergy in improving performance, bring about innovation and change through collaboration. Universities provide well prepared graduates for industries to utilize and graduates acquire employment right after graduation and build experiential knowledge useful for their career development. Experiential learning opportunities exist for faculty and students that may not exist at the universities. Similarly, materials exist in industry for research and education purpose. Increased collaboration between the university and industries facilitate pulling research funding, education and training supports and joint research endeavor. Such collaborations can advance the service mission of universities and serve as means of local and regional economic development. Universities can generate additional resources from such collaboration and part of which could be used for internal reward structure (Ilyas, 2004).

University-Industry collaboration can be viewed from the two perspectives (1) support from universities to industries and (2) support from the industries to universities. The following collaborative supports are suggested for mutual benefits of both universites and industries:

\section{(1) Collaborative Support from Universities: Knowledge Transfer}

Knowledge transfer is understood as the movement of knowledge and discoveries, mainly from academia, to the general public (Ping, 2003; Reid, 2005). It can occur in many ways, for example, through publications, educated students entering the workforce, exchanges at conferences, or by establishing relationships between academia and industry. The current industry-university relationship is being shaped by two global research and development (R\&D) trends that are gradually changing the way academia and industries currently interact. Global trend reveals that industry has a clear incentive to establish $\mathrm{R} \& \mathrm{D}$ collaborations with renowned academic institutions. These trends are turning universities into attractive research and development partners for industries (Reid, 2005). In fact, good academic laboratories operate in international networks, develop cutting-edge research and are constantly being refreshed by the arrival of clever new brains in academia.

Transferring knowledge through education and training: Education and training have been the core activities of higher education institutions in general and school of education in particular. The actual transfer of educated individuals from academia to industry has been studied as a key element of the university-industry interaction (Ilyas, 2004; Hernández-Cuevas, 2006). Therefore, periodic university industry interaction are required to facilitate the promotion of customized training for industry, internships, dissertations in industry, education of industry sponsored individuals, key note lectures from industry resource person, industry-sponsored innovation and creativity competitions. Universities should serve the training and education (HRD) needs of the industries.

Transferring knowledge through consultancy services: Universities should establish a good relationship with the industry and provide research and development support, consultative expert services and technical support to promote performance, increase productivity and promote innovation and change in the industries. From such consulting services, not only industries are benefitted, involved faculties from university also learn to appreciate its consultancy business as an interesting and profitable source of revenue (Hernández-Cuevas, 2006) and can bring the experience of real work situation in the classroom. 
Transferring knowledge through contract research: Through their collaborative efforts with industries, universities should transfer knowledge engaging in contract research. Contract researches are those research works conducted by a university on behalf of an industry as per terms of reference provided by it (Ilyas, 2004). Although Nepalese universities are engaged in such research activities through individuals' approach or personal relation, there is a need for intensifying such services to industries, NGOs and government by establishing a collaborative network.

Transferring knowledge through collaborative research: Universities and industries should engage in collaborative research for the benefit of the both. Research collaborations are understood as co-sponsored research programs, where both, university and industry contribute resources and share the benefits of such collaboration, proportionally to their contributions (Reid, 2005). In general, university contributions can be in the shape of infrastructure (equipment, lab space, etc), highly qualified personnel and intangibles assets (information, contacts, ideas, processes, etc). Industries are usually expected to contribute more financial resources than universities. Collaborative research blends knowledge and experience to generate new knowledge and should be encouraged by both universities and industries.

\section{Transferring Knowledge through Licensing or Spin- out Companies}

Universities should engage its faculties and students in collaborative experimentation and developing innovative technologies or product useful for industries. Such innovative technologies or prototypes will be patent of the university and charges a fee to any third party who wishes to access or use such invention. Writing text books in collaboration with publishing company and sharing the benefits after sales is an example relevant to school of education. However, in some cases the most effective way for a university to maximize its return on its intellectual property is through a spin-out company. This usually means the technology is licensed to a start-up company instead of a well established existing company. In other words, the new born company -co-founded by the university and the research lab that invented the technology- gets a license (usually an exclusive license) to secure the right to use the technology, which would act as its core component for value creation. In this way, the university owns part of the company, but at the same time, the company has more freedom to further develop its exclusively assigned intellectual property. Revision of university regulation to support such knowledge transfer scheme is required.

\section{(2) Collaborative Support from Industries:}

Several collaborative supports are expected from industries to the universities to accomplish transformation of knowledge for economic acceleration. Some of the areas of collaborative supports expected from industries are as follows:

Active involvement in University Industry Dialogues: Industries are expected to actively participate in interaction, discussion and experience sharing to make university programs more relevant to the employers' needs and requirements. Industries may provide feedbacks in the process of curriculum development and revision through such interactions. Industries can supply information on essential competencies required in the workplace and deficiencies of those competencies in university graduates.

Offer venue for experiential learning for students: Industries are expected to offer internship, onthe-job experience or cooperative learning opportunities for undergraduate and graduate students. Industries also are expected to provide students research opportunities beneficial to them in their establishment.

Placement Support. Industries are expected to assist universities for placement of the graduates as interns or as employees in industries/work. Industries are also expected to take part in career 
fair of the universities and recruit students needed for their organization.

Allocate resources for collaborative works beneficial for both industry and University: Industries are expected to allocate resources for organizational development, performance improvement, process consultation, research, education and training. These services can be contracted out to the university.

Collaborative research and innovation: Industries can participate in collaborative research and experimentation with universities for generating new knowledge, technology, or innovation beneficial for both university and industries.

Offer support in the form of stipends or scholarships: Industries can fulfill their social obligation by sponsoring students from weaker and deprived segment of population. Similarly, industries can recognize the talented students and provide with scholarships who could be asset of the industry in the future.

For establishing, maintaining and successful implementation of industry-University collaborative efforts, several conditions are to be fulfilled. First, collaborative agreements must be based on perceived mutual benefits of both sides including willingness and active participation of faculty members and students. Confidentiality should be maintained by all participating collaborating partners. Participating faculty membersare to be provided with appropriatecredit in their promotion and tenure considerations, for their collaboration with industries.

Second, university administration should create an environment conducive to industryUniversity collaboration. Clear policies and guidelines are to be developed to promote such collaboration. Third, a coordinating cell for networking and facilitation in the university and focal points in industries should be created and activated. Fourth, industries may not be aware of the indirect costs that Universities add on to all the direct project costs. Such costs and any exceptions to those should be clearly mentioned in the negotiated agreements. Fifth, Intellectual property ownership should be negotiated with as much flexibility as possible from all collaborating partners so that this does not become an issue that stalls every project. Industries and Universities should encourage expedited process for establishing partnerships by setting up a mechanism for frequent communication on the progress and directions of collaborative projects. Such a mechanism will keep the project moving forward and assure its timely progress.

Finally, universities should take proactive role to bring industries into partnership or collaborative network. A research, innovation and service unit within each of the schools of the university should be established for facilitating the expansion of collaborative networks and increase collaborative works with industries.

\section{Conclusion}

This paper highlighted the context and need for industry and university collaboration to create synergies for mutual benefits. University-industry dialogues, periodic interactions, experts services to the industries, joint innovative research and experimentation, advisement for performance improvement in the industries and HRD support to the industries are proven to be essential aspects for economicacceleration through transformation of knowledge in collaboration with universities. Through such transformation of knowledge industries may gain, broaden the market share and ultimately improve overall performance and productivity. Through collaborative supports, universities may increase quality and relevance of education programs. Similarly universities will have access to professional practice, research work and real work experiences for their students and faculties. Universities will be able to blend knowledge and practice through collaboration with industries and ultimately improve the quality of university education. 
66

Shreeram Lamichhane \& Tanka Nath Sharma

\section{References:}

Börjesson, M., Bruce, A. \& Forsberg, K. (2000). Academia, industry and consulting firms in collaboration: An value-based analysis of different institution. Proceedings of IRIS 23. Loboratorium for Interaction Technology, University of Trollhattan Uddevalla, 2000. L. Svensson, U. Snis, C. Sorensen, H. Fagerlind, T. Lindroth, M. Magnusson, C. Ostlund (eds.).

Campbell, T. I. D. (1997). Public policy for the 21st century: addressing potential conflicts in university-industry collaboration. The Review of Higher Education, 20, 357-379.

Goktepe, (2004). Understanding of UniversityIndustry Relations: A comparative study of organizational and institutional practices of Lund University, Sweden. Ph. D. Theses proposal, Division of Innovation, Lund Institute of Technology, Sweden.

Gray, D. O. (2000). Cooperative research: Government-sponsored industryuniversity cooperative research: An analysis of cooperative research center evaluation approaches. Research Evaluation, 8, 57-67.

Hermelinna, P. (2004). Motivations and barriers related to university-industry collaboration: Applicability and the principle of publicity. Seminar on Innovation, UC Berkeley.

Hernández-Cuevas, C. (2006). Knowledge transfer opportunities for the bioscience sector in Chile. Journal of Technology Management and Innovation. 1(3). P. 4 -15 .

Ilyas, M. (2004). Best practices in Industry - University collaboration. Government,
Industry and University Relationships \& Collaboration - Paper No. 037.

Koester, N. \& Gray, D. O. (1990). A Typology of Industry-University Linking Mechanisms: Implications for Policy and Programs.

Otala, L. (1994). University industry partnership: Implementing lifelong learning. Journal of European Industrial Training, 18(8), 13-18.

Ping, C.J. (2003). Educational imperatives for a new era: University must actively encourage mobility. Retrieved from www.unesco.org/education

Reid, C. (2005): Doing the Deal, A Practitioner's Guide to Lambert. AURIL Spring Conference, Edinburgh.

Rahm, D. (1994). Academic perceptions of university-firm technology transfer. Policy Studies Journal, 22, 267-278.

Srinivas, S. \& Viljamaa, K. (2005). Economic Institutionalization in practice: Development and the "third role" of universities. Paper series from industrial performance center, Local Innovation System Project, MIT.

Tresserras, J., MacGregor, S. \& Espinach X. (2005). SME collaboration as a driver of design research and education development. Engineering and product design education conference 15-16 september 2005, Napier University, Edinburgh, UK.

UNESCO (1998). World Declaration and Framework for Priority Action for Change and Development in Higher Education". Paris, France, . Available on the website: http://www.unesco.org 